\title{
BMJ Open Influencing factors of self-directed learning abilities of medical students of mainland China: a cross-sectional study
}

\author{
Chunhui Yang, ${ }^{1,2}$ Yaxin Zhu, ${ }^{1}$ Hongkun Jiang, ${ }^{3}$ Bo Qu (D) ${ }^{1}$
}

\begin{abstract}
To cite: Yang C, Zhu Y, Jiang $\mathrm{H}$, et al. Influencing factors of self-directed learning abilities of medical students of mainland China: a crosssectional study. BMJ Open 2021;11:e051590. doi:10.1136/ bmjopen-2021-051590
\end{abstract}

- Prepublication history and additional supplemental material for this paper are available online. To view these files, please visit the journal online (http://dx.doi.org/10.1136/ bmjopen-2021-051590).

Received 24 March 2021 Accepted 20 September 2021

Check for updates

(c) Author(s) (or their employer(s)) 2021. Re-use permitted under CC BY-NC. No commercial re-use. See rights and permissions. Published by BMJ.

${ }^{1}$ Institute for International Health Professions Education and Research, China Medical University, Shenyang, Liaoning, China

${ }^{2}$ Department of Resident Training, The First Hospital of China Medical University, Shenyang, Liaoning, China ${ }^{3}$ Department of Pediatrics, The First Hospital of China Medical University, Shenyang, Liaoning, China

Correspondence to

Dr Bo Qu; qubo6666@163.com

\section{ABSTRACT}

Objectives This study aimed to evaluate the level of medical students' self-directed learning (SDL) ability in mainland China and to identify its modifiable influencing factors for medical educators to take measures to improve medical professionals' ability in SDL.

Design This was a cross-sectional study conducted between January and June 2019.

Setting This study involved students from five medical colleges located in the cities of Shenyang, Binzhou, Xuzhou, Shanghai and Guangzhou of mainland China. Participants Participants included 365 medical students and residents sampled by the stratified clustered random method from five medical colleges.

Methods The t-test, F-test and multiple linear regression analyses were performed to test the association between personal and contextual factors of medical students and SDL.

Results The mean total SDL score was 76.12 (SD=10.96), implying that Chinese mainland medical students had moderate SDL ability. A univariate analysis found that the personal characteristics of confidence, students' enjoyment of their specialty, utilisation of library resources, learning goals and habits and academic performance as well as the contextual factors of age, gender, learning resources, family income and group discussion were significantly associated with the total SDL score $(p<0.05)$. Multiple linear regression analyses showed that academic performance, learning goals, confidence, learning resources, utilisation of library resources, family income and age were significantly associated with the total SDL score $(p<0.05)$.

Conclusion Our study indicated that the contextual factors of learning resources, family income and age as well as the personal factors of academic performance, learning goals, confidence and utilisation of library resources were associated with medical students' SDL ability in mainland China. It may be advisable to implement appropriate teaching strategies to improve students' confidence and assist them establish learning goals, as well as to amplify school learning resources and encourage students to use them fully.

\section{INTRODUCTION}

The medical field is considered to have the most quickly evolving knowledge. ${ }^{1}$ Medical professionals need to master the latest medical technologies and methods

\section{Strengths and limitations of this study}

- Student's t-test, analysis of variance and multiple linear regression analysis were used to examine the relationships between self-directed learning (SDL) and influencing factors.

- A stratified clustered random sampling method was used to select participants from five medical schools in different cities representing different regions of China-Shenyang (northeastern), Binzhou (eastern), Xuzhou (central), Shanghai (southeastern) and Guangzhou (southern)—-to improve the sample's representativeness.

- A standardised instrument that assesses medical students' SDL ability was used to make the results more reliable.

- The cross-sectional study design limited our survey factors' correlation with SDL ability and did not permit conclusions concerning causality.

- Our results for the factors of confidence and learning goals were obtained from a single question, rather than a scale, as well as the sample size was small, which could limit the reliability and generalisability of the findings.

to maintain professional competence ${ }^{2}$ and better serve patients. 'A decline in physicians' knowledge with time may result in lower quality of care. It is suggested that medical professionals continue to learn throughout their professional careers. ${ }^{4}$ It is increasingly recognised that medical education should prepare students to be lifelong learners. ${ }^{56}$ Self-directed learning (SDL) is understood as a promising methodology that can promote lifelong learning in medical education. ${ }^{7}$

SDL stems from adult education literature by Knowles. ${ }^{8}$ Knowles defined SDL as 'a process in which individuals take the initiative, with or without the help of others, in diagnosing their learning needs, formulating learning goals, identifying human and material resources for learning, choosing and implementing appropriate learning strategies and evaluating learning outcomes." In other words, SDL entails that individuals 
control and take responsibility for their learning. ${ }^{10}$ To help explain the concept and its elements, Hiemstra and Brockett proposed that learners' personal characteristics and social context are significant factors affecting the SDL process. ${ }^{11}$ Exploring these two factors will allow us to better intervene in medical students' SDL skills.

Several studies have investigated the factors that influence SDL ability. A study conducted of internal medicine residents demonstrated that the personal aspects of motivation and individual characteristics and their development over time as well as the contextual factors of external guidance, residency programme structure and learning barriers influenced the SDL process. ${ }^{12}$ Some studies have reported that the personal characteristic of academic performance has a strong relationship with SDL ability, ${ }^{13} 14$ while another study reported a weaker relationship between the two. ${ }^{15}$ Regarding contextual factors, Premkumar $e t a l^{16}$ proposed that older medical students were better self-directed learners than younger ones in the same cohort and that gender and years of premedical training had no significant effect on SDL ability; however, another study indicated no association between age and SDL ability. ${ }^{17}$ Leatemia et $a l^{18}$ revealed that grade 1 students had higher levels of SDL Readiness (SDLR) than grade 2 students. Other research noted that students from higher grades were more accustomed to SDL principles. ${ }^{19}$ The conclusions from these studies are therefore inconsistent and even contradictory. Some evidence indicates that culture influences students' SDL ability. ${ }^{1820}$ Therefore, it is necessary to explore the factors influencing SDL with students' national background as a reference point.

Several researchers have developed scales to evaluate SDL ability, such as the SDLR Scale, ${ }^{21}{ }^{22}$ the Self-rating Scale of SDL (SRSSDL) ${ }^{23}$ and the Self-directed Learning Instrument (SDLI). ${ }^{6}$ The SDLR and SRSSDL were developed using an exploratory factor analysis approach, and they only analyse content and factor domains. They have the potential weakness of their psychometric properties not being stable when applied to various cultural populations and different types of students. ${ }^{22}{ }^{24}$ The original Chinese version of the SDLI demonstrated good reliability and validity in assessing nursing students' SDL ability in Taiwan. ${ }^{6}$ It has also been used to evaluate SDL ability of students belonging to different cultures and medical programmes, including nursing students from mainland China ${ }^{25}$ and Italy $^{3}$ and medical students from Indian. ${ }^{26}$

With the development of educational technology, learning tools and methods have gradually diversified. In the future, learning behaviours will undergo significant changes. The traditional dominant form of learning based on classroom instruction will also be supplemented by online learning, distance learning or other learning methods, and SDL can take place "using any method in any circumstances at any time. ${ }^{27}$ At present, with the ongoing COVID-19 pandemic, a large number of courses have shifted from didactic instruction in classrooms to learning via digital platforms. ${ }^{28}$ By engaging with SDL effectively, medical students can complete learning assignments and remain informed, and prepare for the future as a lifelong learner.

Better understanding and exploration of influencing factors may be helpful in enhancing students' SDL capacity. Therefore, this study aimed to evaluate what's the level of medical students' SDL ability in mainland China and explore which factors affect SDL. This study would provide information on how students experience SDL and contributes information for evidence-based decision of medical educators to identify strategies to promote them in medical education programmes.

\section{METHODS}

\section{Patient and public involvement}

As the study objects were medical students, patients and the public were not involved in the design, conduct or analysis of our research.

\section{Participants and procedures}

A physician's growth in China goes through three stages: undergraduate education, postgraduate training and continuing education. ${ }^{29}$ Undergraduate education lasts 5 years and is divided into 2 years each of basic sciences and clinical medicine and 1 year of internship. Postgraduate medical training consists of 3 years of resident training and/or 2-4 years of fellowship. Continuing education is a process of lifelong learning based on SDL principles. ${ }^{30} 31$ This study was a cross-sectional survey conducted between January and June 2019. Based on the outcomes about averages $(\overline{\mathrm{x}}=76.7)$ and SDs $(\sigma=11.2)$ of a previous research on SDLI ${ }^{32}$ and the sample size calculation formula $\left(n=\left(\frac{u_{a / 2} \sigma}{\delta}\right)^{2}\right)$ for cross-sectional study, ${ }^{33}$ as well as setting the allowable error $\delta=1.5$ and $a=0.05$, we estimated the sample size required for this study to be no less than 258, including the loss to response rate of $20 \%$. It recruited medical students and residents from five medical campuses located in cities representing the different regions of China: Shenyang (northeastern), Binzhou (eastern), Xuzhou (central), Shanghai (southeastern) and Guangzhou (southern). We applied a stratified clustered random sampling method to select participants from two or three classes for each grade. Subjects were invited to participate after receiving the appropriate information regarding the study's aims and procedures. Data were collected by considering one class as a unit, and questionnaires were collected on the spot. Ultimately, we totally recruited 375 participants, of whom 365 completed the paper-based questionnaire.

\section{Instruments}

The survey questionnaires were self-administered and comprised two sections: basic information and the SDLI. According to Hiemstra and Brockett's SDL model, ${ }^{11}$ we divided the inquiry information into two dimensions: contextual factors consisting of age, gender, grade, 
student leader, family monthly income per capita, school resources and city and personal characteristics variables including confidence, students' enjoyment of their specialty, library resource utilisation, learning goals, academic performance, learning habits and group discussion. The item to evaluate the frequency of using library resources was 'How often do you browse books and periodicals?' The possible answers were 'less than twice a week,' '2 to 3 times a week,' and 'more than 3 times a week.' The item, 'Do you enjoy your specialty?' with a 'yes, neutral, or no' response format was used to assess the degree to which students enjoyed their specialty.

The $\mathrm{SDLI}^{6}$ is a self-administered pencil-paper instrument containing 20 items across the four domains of learning motivation (LM, six items), planning and implementation (PI, six items), self-monitoring (SM, four items) and interpersonal communication (IC, four items). It uses a five-point Likert scale scoring methodstrongly agree (5), agree (4), neutral (3), disagree (2) and strongly disagree (1). The total possible score of the scale is the sum of all item scores, ranging from 20 to 100 , with higher scores indicating higher levels of SDL ability. The internal consistency reliability for the SDLI in this study had an overall Cronbach's $\alpha$ coefficient of 0.944, and for the four domains it was 0.856 (LM), $0.894(\mathrm{PI})$, $0.785(\mathrm{SM})$ and 0.688 (IC). The reliability analysis showed good internal consistency for SDLI to test the SDL ability of medical students in mainland China. The form of the SDLI is included in online supplemental file 1.

\section{Statistical analysis}

Student's t-tests and F-tests were performed to test the association between variables in personal factors, contextual factors and SDLI scores. To evaluate the factors influencing SDL ability, we performed a multiple linear regression analysis with the total SDLI score as the dependent variable and personal and contextual factors as independent variables. The enter method was employed to enter the independent variables of all models. Statistical analyses were conducted using SPSS V.21.0 for Windows. Statistical significance was set at $\mathrm{p}<0.05$.

\section{RESULTS}

\section{Contextual and personal characteristics of medical students}

A total of 375 medical students participated in the survey, and 365 completed the questionnaires, with a response rate of $97.3 \%$. The mean total SDL score was 76.12 $(\mathrm{SD}=10.96)$, which was comparable to results obtained in Taiwan, implying that the SDL ability of medical students in mainland China was moderate. ${ }^{5}$ The contextual characteristics of the participants are presented in table 1 . There were 213 female participants $(58.36 \%)$ and 152 male participants (41.64\%). Their ages ranged from 20 to 42 years, with a mean age of 25.01 years $(\mathrm{SD}=2.69)$, which was negatively associated with the SDL scores total $(\mathrm{r}=-0.059$, $\mathrm{p}>0.05)$. A total of 212 participants $(58.08 \%)$ were residents, and the rest were medical students. Approximately one-third of the participants were class leaders and had stronger interpersonal communication skills than those who were not leaders. About half of the students who felt that their school had rich learning resources had higher SDLI scores. The F-test and t-test revealed significant differences in the SDL scores between different student groups of age, gender, family monthly income per capita and learning resources $(p<0.05)$. Male students scored higher than female students. Medical students whose family monthly income was less than $¥ 2000$ per capita had the highest scores. No statistically significant differences in SDL and the four domain scores were found between the different grade, student leader and city groups.

Personal factors are shown in table 2. Over half of the medical students reported feeling confident $(\mathrm{n}=189$, $51.78 \%$ ), and they had higher SDL scores when compared with students who did not. Overall, $70 \%$ of students who enjoyed their specialty obtained the highest SDL scores, while students who were uncertain had the lowest scores. The majority of the participants had good to moderate learning goals, learning habits and academic performance $(95.89 \%, 91.51 \%$ and $95.07 \%$, respectively), and they obtained higher SDL scores. The F-test and t-test demonstrated significant differences in SDL scores for all students' inputs regarding personal characteristics of different student groups of confidence, enjoyment of their specialty, utilisation of library resources, learning goals and habits, academic performance and group discussion $(\mathrm{p}<0.05)$.

\section{Exploratory investigation of possible related factors of medical students' SDL ability}

The results of the multiple linear regression analysis are shown in table 3 . The independent variables of all models are listed according to the value of the standardised coefficient $\beta$. Among the contextual and personal characteristics, academic performance, learning goals, confidence, school learning resources and frequency of the utilisation of library resources were positively correlated with the total SDL scores of the medical students $(\mathrm{p}<0.05)$, with standardised coefficients of $0.397,0.305,0.241,0.125$ and 0.093 , respectively. Family income and age of participants were negatively associated with SDL $(\mathrm{p}<0.05)$, with standardised coefficients of -0.189 and -0.125 , respectively.

\section{DISCUSSION}

Our study found that the personal characteristics of academic performance, confidence as well as the contextual factors of learning resources, family income and age were significantly associated with medical students' SDL ability in mainland China $(\mathrm{p}<0.05)$. Identifying modifiable influencing factors for medical educators to prepare medical students' SDL ability might become meaningful.

The analysis of the association between academic performance and SDL scores showed significant differences. Students with better academic performance were found to have significantly higher SDLI scores. Our 
Table 1 Relationship between contextual factors and SDL $(n=365)$

\begin{tabular}{|c|c|c|c|c|c|c|}
\hline Variable & n (\%) & LM & PI & SM & IC & SDL \\
\hline Total participants & 365 (NA) & $23.8 \pm 4.98$ & $22.22 \pm 5.15$ & $15.40 \pm 3.21$ & $15.25 \pm 3.27$ & $76.12 \pm 10.96$ \\
\hline \multicolumn{7}{|l|}{ Gender* } \\
\hline Male & $152(41.64)$ & $24.39 \pm 3.93 \dagger$ & $22.89 \pm 4.26 \dagger$ & $15.64 \pm 2.44 \dagger$ & $15.54 \pm 2.68 \dagger$ & $78.48 \pm 11.28 \dagger$ \\
\hline Female & $213(58.36)$ & $23.38 \pm 3.66$ & $21.74 \pm 4.03$ & $14.81 \pm 2.33$ & $14.52 \pm 2.56$ & $74.45 \pm 10.43$ \\
\hline \multicolumn{7}{|l|}{ Grade* } \\
\hline Student & $153(41.92)$ & $23.79 \pm 3.85$ & $22.18 \pm 4.10$ & $14.90 \pm 2.34$ & $14.78 \pm 2.58$ & $75.65 \pm 10.77$ \\
\hline Resident & $212(58.08)$ & $23.81 \pm 3.78$ & $22.25 \pm 4.21$ & $15.34 \pm 2.45$ & $15.06 \pm 2.71$ & $76.46 \pm 11.11$ \\
\hline \multicolumn{7}{|l|}{ Student leader } \\
\hline Yes & $130(35.62)$ & $23.94 \pm 3.67$ & $22.40 \pm 3.95$ & $15.37 \pm 2.36$ & $15.45 \pm 2.35$ & $77.15 \pm 9.85$ \\
\hline No & $233(63.84)$ & $23.73 \pm 3.89$ & $22.11 \pm 4.29$ & $15.04 \pm 2.44$ & $14.68 \pm 2.79$ & $75.57 \pm 11.54$ \\
\hline \multicolumn{7}{|c|}{ Family monthly income per capitaf } \\
\hline$<¥ 2000$ & 68 (18.63) & $25.13 \pm 3.17 \dagger$ & $23.34 \pm 4.18 \dagger$ & $15.90 \pm 2.32 \dagger$ & $15.94 \pm 2.71 \dagger$ & $80.31 \pm 10.14 \dagger$ \\
\hline$¥ 2000-¥ 4000$ & $176(48.22)$ & $23.05 \pm 3.80$ & $21.44 \pm 4.02$ & $14.71 \pm 2.14$ & $14.34 \pm 2.43$ & $73.53 \pm 10.17$ \\
\hline$>¥ 4000$ & $121(33.15)$ & $24.15 \pm 3.90$ & $22.72 \pm 4.18$ & $15.39 \pm 2.69$ & $15.27 \pm 2.73$ & $77.53 \pm 11.60$ \\
\hline \multicolumn{7}{|c|}{ Learning resources ${ }^{*}$} \\
\hline Rich & $193(52.88)$ & $24.63 \pm 3.56 \dagger$ & $23.13 \pm 3.79 \dagger$ & $15.64 \pm 2.35 \dagger$ & $15.38 \pm 2.57 \dagger$ & $78.79 \pm 10.27 \dagger$ \\
\hline No & $172(47.12)$ & $22.87 \pm 3.86$ & $21.19 \pm 4.33$ & $14.62 \pm 2.36$ & $14.45 \pm 2.67$ & $73.13 \pm 10.96$ \\
\hline \multicolumn{7}{|l|}{ City $\ddagger$} \\
\hline Shenyang & 56 (15.34) & $23.75 \pm 3.50$ & $22.82 \pm 4.24$ & $15.34 \pm 2.54$ & $14.96 \pm 2.95$ & $76.88 \pm 11.76$ \\
\hline Shanghai & 89 (24.38) & $23.34 \pm 3.69$ & $21.70 \pm 4.50$ & $14.98 \pm 2.40$ & $14.76 \pm 2.49$ & $74.78 \pm 10.94$ \\
\hline Xuzhou & 81 (22.19) & $24.20 \pm 3.97$ & $22.16 \pm 3.85$ & $15.57 \pm 2.31$ & $15.35 \pm 2.75$ & $77.27 \pm 10.34$ \\
\hline Binzhou & $74(20.27)$ & $24.23 \pm 3.72$ & $23.05 \pm 4.40$ & $15.27 \pm 2.48$ & $15.27 \pm 2.50$ & $77.82 \pm 11.41$ \\
\hline Guangzhou & 65 (17.81) & $23.49 \pm 4.07$ & $21.54 \pm 3.55$ & $14.60 \pm 2.28$ & $14.31 \pm 2.61$ & $73.94 \pm 10.23$ \\
\hline
\end{tabular}

*Learner's t-test.

†Statistically significant associations are bolded $(p<0.05)$.

‡One-way ANOVA.

ANOVA, Analysis of Variance; IC, interpersonal communication; LM, learning motivation; NA, not applicable; PI, planning and implementing; SDL, self-directed learning; SM, self-monitoring.

findings were consistent with a study showing that SDL skills such as the identification of learning needs, the utilisation of learning resources, the management of learning processes and planning time were related to academic success. ${ }^{34} 35$ Nevertheless, several previous studies concluded that academic performance had no significant effect on SDL scores, as SDL may not be necessary for learning foundational knowledge, provided students are given specific instructions on what to study. ${ }^{16}$ Our findings probably due to the fact that the participants were senior medical students and residents who should be proficient in comprehensive clinical practice skills, which may need SDL to master.

We found that confidence was associated with medical students' SDL ability, the higher the confidence, the higher the SDLI score. This was in line with a study showing that students with greater confidence in controlling their learning process were more self-directed than others. ${ }^{21}$ Confidence has been proposed as a factor in readiness for SDL. ${ }^{30}$ As students gained confidence in their SDL ability, they were more willing to become independent in their learning. ${ }^{37}$ Additionally, one study conducted of residents indicated that different levels of confidence affected how they approached SDL. Over time, residents naturally become more confident when identifying and using the appropriate resources for a given objective, ${ }^{12}$ which enabled the SDL process.

Regarding learning resources, students who deemed that their schools had abundant learning resources and frequently used library resources had higher SDLI scores. Students' evaluations of the richness of their school's learning resources varied for the same school: the stronger their SDL ability, the better their exploration and utilisation of learning resources. Knowles ${ }^{9}$ and Iwasiw ${ }^{38}$ identified learning resources as an important part of the SDL process. Our findings were congruent with previous work suggesting that medical students who had higher scores on SDL scales used learning resources such as libraries and electronic medical databases more frequently and spent more time studying independently. ${ }^{39} \mathrm{~A}$ recent study implemented a case-based SDL activity in a first-year medical school course. The study graded students, not 


\begin{tabular}{|c|c|c|c|c|c|c|}
\hline Variable & n (\%) & LM & PI & SM & IC & SDL \\
\hline Total participants & 365 (NA) & $23.8 \pm 4.98$ & $22.22 \pm 5.15$ & $15.40 \pm 3.21$ & $15.25 \pm 3.27$ & $76.12 \pm 10.96$ \\
\hline \multicolumn{7}{|l|}{ Confidence $^{\star}$} \\
\hline Yes & $189(51.78)$ & $25.07 \pm 3.41 \dagger$ & $23.75 \pm 3.91 \dagger$ & $16.13 \pm 2.28 \dagger$ & $15.94 \pm 2.52 \dagger$ & $80.89 \pm 9.99 \dagger$ \\
\hline No & $176(48.22)$ & $22.44 \pm 3.74$ & $20.58 \pm 3.79$ & $14.11 \pm 2.08$ & $13.88 \pm 2.37$ & $71.00 \pm 9.57$ \\
\hline \multicolumn{7}{|c|}{ Enjoyment of specialty $\ddagger$} \\
\hline Yes & $257(70.41)$ & $24.84 \pm 3.36 \dagger$ & $22.99 \pm 4.12 \dagger$ & $15.58 \pm 2.29 \dagger$ & $15.37 \pm 2.61 \dagger$ & $78.78 \pm 10.24 \dagger$ \\
\hline Neutral & $46(12.60)$ & $20.80 \pm 3.79$ & $19.33 \pm 4.13$ & $13.83 \pm 2.37$ & $13.52 \pm 2.47$ & $67.48 \pm 10.27$ \\
\hline No & 62 (16.99) & $21.73 \pm 3.54$ & $21.16 \pm 3.12$ & $14.37 \pm 2.40$ & $14.24 \pm 2.47$ & $71.50 \pm 9.54$ \\
\hline \multicolumn{7}{|c|}{ Utilisation of library resources } \\
\hline$<$ Twice a week & $237(64.93)$ & $23.30 \pm 3.59 \dagger$ & $21.76 \pm 4.01 \dagger$ & $14.74 \pm 2.34 \dagger$ & $14.46 \pm 2.61 \dagger$ & $74.27 \pm 10.39 \dagger$ \\
\hline 2-3 times a week & $77(21.10)$ & $24.36 \pm 4.46$ & $22.77 \pm 4.64$ & $15.86 \pm 2.38$ & $15.92 \pm 2.66$ & $78.91 \pm 11.99$ \\
\hline$>3$ times a week & $51(13.97)$ & $25.27 \pm 3.21$ & $23.53 \pm 3.79$ & $16.02 \pm 2.34$ & $15.71 \pm 2.30$ & $80.53 \pm 9.93$ \\
\hline \multicolumn{7}{|l|}{ Learning goals $\ddagger$} \\
\hline Clear & $134(36.71)$ & $25.81 \pm 3.28 \dagger$ & $23.97 \pm 4.06 \dagger$ & $16.00 \pm 2.36 \dagger$ & $15.82 \pm 2.68 \dagger$ & $81.60 \pm 10.03 \dagger$ \\
\hline Neutral & $216(59.18)$ & $22.84 \pm 3.46$ & $21.32 \pm 3.81$ & $14.75 \pm 2.22$ & $14.56 \pm 2.42$ & $73.47 \pm 9.85$ \\
\hline No & $15(4.11)$ & $19.67 \pm 4.29$ & $19.53 \pm 4.56$ & $13.53 \pm 3.23$ & $12.67 \pm 3.09$ & $65.40 \pm 12.61$ \\
\hline \multicolumn{7}{|c|}{ Academic performance $\neq$} \\
\hline Good & $175(47.95)$ & $25.03 \pm 3.27 \dagger$ & $23.65 \pm 3.68 \dagger$ & $16.04 \pm 2.37 \dagger$ & $15.58 \pm 2.78 \dagger$ & $80.30 \pm 9.97 \dagger$ \\
\hline Neutral & $172(47.12)$ & $22.88 \pm 3.79$ & $21.20 \pm 4.08$ & $14.48 \pm 2.10$ & $14.60 \pm 2.25$ & $73.17 \pm 10.02$ \\
\hline Poor & $18(4.93)$ & $20.67 \pm 4.59$ & $18.06 \pm 3.92$ & $13.00 \pm 2.25$ & $12.00 \pm 2.52$ & $63.72 \pm 10.66$ \\
\hline \multicolumn{7}{|l|}{ Learning habits } \\
\hline Good & $93(25.48)$ & $25.75 \pm 3.06 \dagger$ & $24.45 \pm 3.42 \dagger$ & $16.37 \pm 2.13 \dagger$ & $15.84 \pm 2.72 \dagger$ & $82.41 \pm 9.15 \dagger$ \\
\hline Neutral & $241(66.03)$ & $23.32 \pm 3.72$ & $21.77 \pm 3.92$ & $14.84 \pm 2.28$ & $14.65 \pm 2.50$ & $74.57 \pm 10.27$ \\
\hline Poor & $31(8.49)$ & $21.71 \pm 4.18$ & $19.03 \pm 4.90$ & $13.97 \pm 2.85$ & $14.58 \pm 3.06$ & $69.29 \pm 12.93$ \\
\hline \multicolumn{7}{|l|}{ Group discussion $\ddagger$} \\
\hline Regular & $59(16.16)$ & $24.36 \pm 3.46 \dagger$ & $23.19 \pm 3.77 \dagger$ & $15.29 \pm 2.35$ & $15.31 \pm 2.61 \dagger$ & $78.14 \pm 10.56 \dagger$ \\
\hline Neutral & $267(73.15)$ & $23.89 \pm 3.81$ & $22.28 \pm 4.08$ & $15.23 \pm 2.37$ & $15.00 \pm 2.62$ & $76.41 \pm 10.63$ \\
\hline Never & 39 (10.68) & $22.33 \pm 3.40$ & $20.31 \pm 4.74$ & $14.46 \pm 2.69$ & $14.00 \pm 2.8$ & $71.10 \pm 12.53$ \\
\hline
\end{tabular}

*Learner's t-test.

†Statistically significant associations are bolded $(p<<0.05)$.

¥One-way ANOVA

ANOVA, Analysis of Variance; IC, interpersonal communication; LM, learning motivation; NA, not applicable; PI, planning and implementing;

$\mathrm{SDL}$, self-directed learning; SM, self-monitoring.

on the accuracy of their differential and final diagnoses but on their ability to provide a rationale and supporting documentation to justify their conclusions. The students perceived that the activity helped them develop SDL skills. ${ }^{40}$

Students from middle-income families obtained the lowest SDLI scores, while those from low-income families obtained the highest scores. This was different from previous studies that concluded that income level did not affect SDL. ${ }^{341}$ This difference might be due to a discrepancy in culture. Most students from middle-income families living in a comfortable environment might tend to be satisfied with their current living status and lack a sense of crisis. However, students from low-income families might be more eager to learn because they wish to develop themselves to improve their future living status and upgrade their social class.

The findings of this study also demonstrated that age was negatively associated with students' SDLI scores, differing from previous studies that revealed no correlation between student age and SDL skills. ${ }^{13} 18$ This result disagreed with previous studies indicating that older students had significantly higher scores than younger students. ${ }^{19}$ The original concept of SDL theory was based on the principles of adult education, suggesting that it is more suitable for adult learners ${ }^{9}$; ; yet, in other studies, SDL was proven effective with children in preliminary and secondary education. ${ }^{7}$ A study elucidated that SDLR was not attributable to age itself but, rather, to the students' experiences. ${ }^{43}$ These findings suggest a dichotomy in 
Table 3 Multiple linear regression analyses for influencing factors associated with SDL ( $n=365$ )

\begin{tabular}{|c|c|c|c|c|c|}
\hline \multirow[b]{2}{*}{ Factor } & \multicolumn{2}{|c|}{ Unstandardised coefficient } & \multirow{2}{*}{$\begin{array}{l}\text { Standardised coefficient } \\
\beta\end{array}$} & \multirow[b]{2}{*}{$\mathbf{t}$} & \multirow[b]{2}{*}{$P$ value } \\
\hline & B & SE & & & \\
\hline \multicolumn{6}{|l|}{ Academic performance } \\
\hline Good & 8.707 & 2.351 & $0.397 \dagger$ & 3.703 & $<0.001$ \\
\hline Neutral & 5.747 & 2.237 & $0.262^{*}$ & 2.569 & 0.011 \\
\hline \multicolumn{6}{|l|}{ Learning goals§ } \\
\hline Clear & 6.930 & 2.689 & $0.305 \dagger$ & 2.577 & 0.010 \\
\hline Neutral & 3.875 & 2.509 & 0.174 & 1.544 & 0.123 \\
\hline Confidence: yes & 5.286 & 1.000 & $0.241 \dagger$ & 5.286 & $<0.001$ \\
\hline Learning resources: rich & 2.743 & 0.968 & $0.125 \dagger$ & 2.833 & 0.005 \\
\hline \multicolumn{6}{|c|}{ Utilisation of library resources $q$} \\
\hline 2-3 times a week & 2.517 & 1.158 & $0.093^{*}$ & 2.173 & 0.030 \\
\hline$>3$ times a week & 2.279 & 1.375 & 0.072 & 1.658 & 0.098 \\
\hline \multicolumn{6}{|c|}{ Family monthly income per capita** } \\
\hline$=¥ 2000-¥ 4000$ & -4.142 & 1.227 & $-0.189 \dagger$ & -3.376 & 0.001 \\
\hline$>¥ 4000$ & -1.636 & 1.292 & -0.070 & -1.266 & 0.206 \\
\hline Age & -0.511 & 0.209 & -0.125 & -2.451 & 0.015 \\
\hline \multicolumn{6}{|l|}{ Learning habits†† } \\
\hline Good & 2.625 & 2.057 & 0.105 & 1.276 & 0.203 \\
\hline Neutral & 0.209 & 1.792 & 0.009 & 0.116 & 0.907 \\
\hline \multicolumn{6}{|l|}{ Group discussion $\ddagger \ddagger$} \\
\hline Regular & 3.041 & 1.879 & 0.102 & 1.618 & 0.107 \\
\hline Neutral & 0.871 & 1.596 & 0.035 & 0.546 & 0.586 \\
\hline Gender: male & 1.659 & 0.925 & 0.075 & 1.793 & 0.074 \\
\hline Student leader: yes & 1.174 & 0.965 & 0.051 & 1.217 & 0.224 \\
\hline Grade: resident & 0.822 & 1.061 & 0.037 & 0.774 & 0.439 \\
\hline \multicolumn{6}{|l|}{ City§§ } \\
\hline Shenyang & 0.896 & 1.778 & 0.030 & 0.504 & 0.615 \\
\hline Shanghai & -2.544 & 1.566 & -0.100 & -1.624 & 0.105 \\
\hline Xuzhou & -2.420 & 1.621 & -0.091 & -1.493 & 0.136 \\
\hline Binzhou & -0.648 & 1.586 & -0.025 & -0.431 & 0.666 \\
\hline \multicolumn{6}{|l|}{ Enjoyment of specialtyףी } \\
\hline Yes & 0.285 & 1.370 & 0.012 & 0.208 & 0.836 \\
\hline Neutral & -2.835 & 1.688 & -0.086 & -1.679 & 0.094 \\
\hline
\end{tabular}

SDLI score was the dependent variable.

Statistically significant associations are bolded $(p<0.05)$.

${ }^{*} \mathrm{P}<0.05$.

$\dagger P<0.01$

$\ddagger$ Reference group $=$ poor.

$\S$ Reference group $=$ no.

IReference group=poor. Reference group $=<$ Twice a week.

${ }^{* *}$ Reference group $<¥ 2000$.

††Reference group=Poor.

$\ddagger \ddagger$ Reference group $=$ Never.

$\S \S$ Reference group=Guangzhou.

१ीReference group=No.

$B$, regression coefficient; SDL, self-directed learning; SDLI, Self-directed Learning Instrument. 
the understanding of the association between SDL and age. A further research on the influence of age on SDL is needed.

A limitation of this study is that the cross-sectional study design was implemented at only one point in time, which may limit our survey factors' correlation with SDL ability and prevent the drawing of causality conclusions. Additionally, results for the factors of confidence and learning goals were obtained from a single question, rather than a scale, which could limit the reliability of the findings. Moreover, our participants just from mainland China as well as the sample size was small, which might hinder the generalisability of the study to other countries. Therefore, a further longitudinal study and a well-founded study design with expanded sample size including different regional and cultural participants should be used for this subject.

\section{CONCLUSION}

The present study demonstrated that the SDL ability of medical students in mainland China was moderate. Several factors influencing SDL were identified, including the contextual factors of age, family income and learning resources as well as the personal factors of academic performance, learning goals, confidence and utilisation of library resources. Younger students from low-income families or those with good academic performance had higher SDL ability. It may be useful that medical students improve confidence and establish clear learning goals to enhance SDL ability. Concurrently, medical colleges educators should amplify learning resources and encourage students to make good use of them, as well as implement appropriate teaching strategies, such as problem-based learning to foster medical students' confidence and assist them in setting learning goals to facilitate effective SDL.

Acknowledgements The authors thank all participants in this research and team members for help with sample collection.

Contributors $\mathrm{BQ}$ designed the study and revised the manuscript. $\mathrm{CY}$ wrote the manuscript. YZ and CY participated in the data analysis and revised the manuscript. $\mathrm{HJ}$ reviewed the manuscript. All authors read and approved the final manuscript.

Funding This study was supported by the 2017 Liaoning Distinguished Professor (grant number 9) and the 2017 Liaoning Bai Qian Wan Talents Program (grant number 11).

Competing interests None declared.

Patient consent for publication Not applicable.

Ethics approval The study was approved by the Bioethics Advisory Commission of China Medical University (grant number 2019048). Participation in the study was voluntary, and informed consent was obtained. All the information was kept confidential.

Provenance and peer review Not commissioned; externally peer reviewed.

Data availability statement All data relevant to the study are included in the article or uploaded as supplementary information. All data are available upon reasonable request.

Supplemental material This content has been supplied by the author(s). It has not been vetted by BMJ Publishing Group Limited (BMJ) and may not have been peer-reviewed. Any opinions or recommendations discussed are solely those of the author(s) and are not endorsed by BMJ. BMJ disclaims all liability and responsibility arising from any reliance placed on the content. Where the content includes any translated material, BMJ does not warrant the accuracy and reliability of the translations (including but not limited to local regulations, clinical guidelines, terminology, drug names and drug dosages), and is not responsible for any error and/or omissions arising from translation and adaptation or otherwise.

Open access This is an open access article distributed in accordance with the Creative Commons Attribution Non Commercial (CC BY-NC 4.0) license, which permits others to distribute, remix, adapt, build upon this work non-commercially, and license their derivative works on different terms, provided the original work is properly cited, appropriate credit is given, any changes made indicated, and the use is non-commercial. See: http://creativecommons.org/licenses/by-nc/4.0/.

ORCID iD

Bo Qu http://orcid.org/0000-0003-2526-9690

\section{REFERENCES}

1 Williamson JW, German PS, Weiss R, et al. Health science information management and continuing education of physicians. A survey of U.S. primary care practitioners and their opinion leaders. Ann Intern Med 1989;110:151-60.

2 Galvin E, Wiese A, Dahly D, Emer G, Anel W, Darren D, et al. Maintenance of professional competence in Ireland: a national survey of doctors' attitudes and experiences. BMJ Open 2020;10:e042183.

3 Miles PV. Maintenance of certification: the profession's response to physician quality. Ann Fam Med 2011;9:196-7.

4 Choudhry NK, Fletcher RH, Soumerai SB. Systematic review: the relationship between clinical experience and quality of health care. Ann Intern Med 2005;142:260-73.

5 Towle A, Cottrell D. Self directed learning. Arch Dis Child 1996;74:357-9.

6 Cheng S-F, Kuo C-L, Lin K-C, et al. Development and preliminary testing of a self-rating instrument to measure self-directed learning ability of nursing students. Int J Nurs Stud 2010;47:1152-8.

7 Murad MH, Varkey P. Self-directed learning in health professions education. Ann Acad Med Singap 2008;37:580-90.

8 Knowles M, Holton E, Swanson R. The adult learner: the definitive classic in adult education and human resource development. 6th ed. New York, NY: Elsevier, 2005.

9 Knowles M. Self-Directed learning: a guide for learners and teachers. Cambridge, NY: Pearson Learning Cambridge Adult Education, 1975.

10 Jennings SF. Personal development plans and self-directed learning for healthcare professionals: are they evidence based? Postgrad Med J 2007;83:518-24.

11 Hiemstra R, Brockett RG. Reframing the meaning of Self-Directed learning: an updated Modeltt. Adult education research conference, 2012. Available: https://newprairiepress.org/aerc/2012/papers/22

12 Sawatsky AP, Ratelle JT, Bonnes SL, et al. A model of self-directed learning in internal medicine residency: a qualitative study using grounded theory. BMC Med Educ 2017;17:31.

$13 \mathrm{Khiat} H$. Academic performance and the practice of self-directed learning: the adult student perspective. J Furth High Educ 2017;41:44-59.

14 Lounsbury JW, Levy JJ, Park S-H, et al. An investigation of the construct validity of the personality trait of self-directed learning. Learn Individ Differ 2009;19:411-8.

15 Abraham RR, Fisher M, Kamath A, et al. Exploring first-year undergraduate medical students' self-directed learning readiness to physiology. Adv Physiol Educ 2011;35:393-5.

16 Premkumar K, Pahwa P, Banerjee A, et al. Does medical training promote or deter self-directed learning? A longitudinal mixedmethods study. Acad Med 2013;88:1754-64.

17 Phillips BN, Turnbull BJ, He FX. Assessing readiness for self-directed learning within a non-traditional nursing cohort. Nurse Educ Today 2015;35:e1-7.

18 Leatemia LD, Susilo AP, van Berkel H. Self-directed learning readiness of Asian students: students perspective on a hybrid problem based learning curriculum. Int J Med Educ 2016;7:385-92.

19 Frambach JM, Driessen EW, Chan L-C, et al. Rethinking the globalisation of problem-based learning: how culture challenges selfdirected learning. Med Educ 2012;46:738-47.

20 Kidane $\mathrm{HH}$, Roebertsen $\mathrm{H}$, van der Vleuten CPM. Students' perceptions towards self-directed learning in Ethiopian medical schools with new innovative curriculum: a mixed-method study. BMC Med Educ 2020;20:7.

21 Guglielmino LM. Development of the self-directed learning readiness scale. Athens, GA: University of Georgia, 1977. 
22 Fisher M, King J, Tague G. Development of a self-directed learning readiness scale for nursing education. Nurse Educ Today 2001;21:516-25.

23 Williamson SN. Development of a self-rating scale of self-directed learning. Nurse Res 2007;14:66-83.

24 Hendry GD, Ginns P. Readiness for self-directed learning: validation of a new scale with medical students. Med Teach 2009;31:918-20.

25 Shen W-Q, Chen H-L, Hu Y. The validity and reliability of the selfdirected learning instrument (SDLI) in mainland Chinese nursing students. BMC Med Educ 2014;14:108.

26 Bhandari B, Chopra D, Singh K. Self-directed learning: assessment of students' abilities and their perspective. Adv Physiol Educ 2020;44:383-6.

27 Benedict N, Schonder K, McGee J, Neal B, Kristine S, James M. Promotion of self-directed learning using virtual patient cases. Am J Pharm Educ 2013;77:151.

28 Dost S, Hossain A, Shehab M, et al. Perceptions of medical students towards online teaching during the COVID-19 pandemic: a national cross-sectional survey of 2721 UK medical students. BMJ Open 2020;10:e042378.

29 State Council General Office of China. Guidelines on accelerating the Innovative development of Medical Education of the State Council General Office, 2020. Available: http://www.gov.cn/zhengce/content/ 2020-09/23/content_5546373.htm

30 Robinson JD, Persky AM. Developing self-directed learners. Am J Pharm Educ 2020;84:847512.

31 Kaulback MK. Correlating Self-directed learning abilities to lifelong learning orientation in Baccalaureate nursing students. Nurse Educ 2020;45:347-51.

32 Cadorin L, Cheng S-F, Palese A. Concurrent validity of self-rating scale of self-directed learning and self-directed learning instrument among Italian nursing students. BMC Nurs 2016;15:20.
33 Sun ZQ. Medical statistics. Beijing: People's Medical Publishing House, 2002: 580-6.

34 Tekkol İlkay Așkin, Demirel M. An investigation of self-directed learning skills of undergraduate students. Front Psychol 2018;9:2324.

35 Chitkara MB, Satnick D, Lu W-H, et al. Can individualized learning plans in an advanced clinical experience course for fourth year medical students foster Self-Directed learning? BMC Med Educ 2016;16:232.

36 McGrath D, Crowley L, Rao S, et al. Outcomes of Irish graduate entry medical student engagement with self-directed learning of clinical skills. BMC Med Educ 2015;15:21.

37 Kerr D, Ratcliff J, Tabb L, et al. Undergraduate nursing student perceptions of directed self-guidance in a learning laboratory: an educational strategy to enhance confidence and workplace readiness. Nurse Educ Pract 2020;42:102669.

38 Iwasiw CL. The role of the teacher in self-directed learning. Nurse Educ Today 1987;7:222-7.

39 Shokar GS, Shokar NK, Romero CM, et al. Self-directed learning: looking at outcomes with medical students. Fam Med 2002;34:197-200.

40 Hill M, Peters M, Salvaggio M, et al. Implementation and evaluation of a self-directed learning activity for first-year medical students. Med Educ Online 2020;25:1717780.

41 Jeong D, Presseau J, EIChamaa R, et al. Barriers and facilitators to self-directed learning in continuing professional development for physicians in Canada: a scoping review. Acad Med 2018;93:1245-54.

42 Manning PR, Clintworth WA, Sinopoli LM, et al. A method of selfdirected learning in continuing medical education with implications for recertification. Ann Intern Med 1987;107:909-13.

43 O'Shea E. Self-directed learning in nurse education: a review of the literature. J Adv Nurs 2003;43:62-70. 